Quite recently a new possibility has opened for de ciding, by experiment, the relevancy of the BoseEinstein way of counting, without entering into the obscurities of complicated and approximate calculations. Ordinary helium $\left(\mathrm{He}^{4}\right)$ has an extremely rare isotope, $\mathrm{He}^{3}$, which occurs in atmospheric helium, itself a very rare gas, only in a ratio of $1: 1,200,000$. There are very definite reasons, which cannot be explained here, which force the physicist to apply a different way of counting to helium-3 from that used for ordinary helium. According to this particular way of counting, called 'Fermi-Dirac statistics', the helium-3 atoms, at least if they are considered as force-free, would show no condensation of the kind derived for 'Bose-Einstein particles'. The manner in which one counts the permutations of 'Fermi-Dirac-particles' does not imply individuality of the molecules either; however, it has a peculiar feature in addition, in that it does not permit several particles of the same kind to have exactly the same velocity. This particular feature of the 'Fermi-Dirac particles' precludes a condensation mechanism of the type encountered for 'Bose-Einstein particles'.

The extreme rarity of helium-3 had prevented ex. periments with this isotope until recently. Now, appreciable quantities of this isotope can be obtained from the Atomic Energy Commission, since it is one of the many products which can be made by using the strong neutron beams of an atomic pile.

It has recently been possible to liquefy a fraction of a cubic centimetre of pure helium -3 and to measure its vapour pressure curve ${ }^{8}$. The critical temperature and the critical pressure are about $3 \cdot 34^{\circ}$ abs. and $875 \mathrm{~mm}$. mercury respectively.

The experiment in Chicago referred to in the beginning of the present article attacks directly the question of whether or not liquid helium-3 at some temperature in the neighbourhood of $2^{\circ}$ abs. becomes superfluid like helium-4. The liquid helium is being pressed through a fine capillary, and one measures the flow velocity at different temperatures. While for liquid helium-4 this flow velocity has, at $2 \cdot 19^{\circ}$ abs., a discontinuity and for lower temperatures suddenly becomes extremely large, the experiments with helium-3 show no remarkable change of the flow properties from $3^{\circ}$ abs. down to $1 \cdot 05^{\circ}$ abs. The viscosity is of the same order of magnitude as that of liquid helium-4 above $2 \cdot 19^{\circ}$, and considered as a function of temperature it shows no discontinuity in the whole temperature-range measured. This is a negative result, true, still a quite decisive one, since it settles a qualitative question. One might hold definite judgment in suspense until the experiment is extended to a still lower temperature. However, the temperature of $1.05^{\circ}$ abs. reached so far ought to be quite sufficient to ascertain that the BoseEinstein condensation mechanism represents the key to the understanding of the unique fluid state represented by helium 4 at temperatures below $2 \cdot 19^{\circ}$.

${ }^{1}$ Osborne, D. W., Weinstock, B., and Abraham, B. M., Amer. Phys. Soc. meeting at Berkeley, Calif., Feb. 5, 1949, Phys. Rev., March 15.

' London, F., Nature, 141, 643 (1938) ; Phys. Rev., 54, 947 (1938) Physical Society Conference Report of a Conference on

${ }^{3}$ Einstein, A., Ber. Preuss. Akad. Wiss., Berlin, 261 (1924), 3 (1925).

4 Tisza, L., Nature, 141, 913 (1938); C.R. Acad. Sci., Paris, 207, 1035 1185 (1938); Phys. Rev., 72,838 (1947).

s Landau, L., J. Phys. U.S.S.R., 5, 71 (1941).

- Kapitza, P., J. Phys. U.S.S.R., 5, 59 (1941).

7 Peshkov, V., J. Phys. U.S.S.R., 8, 381 (1944); 10, 389 (1946).

sydoriak, S. G., Grilly, E. R., and Hammel, E. F., Phys. Rev. 75, 303 (1949).

\section{WEATHER AND FARMING IN INDIA $|j|$.}

$T_{\mathrm{d}}^{\mathrm{H}}$ HE world pattern agriculture is largely determined $\mathrm{ky}$ tha world pattern of climate, and where wide fluting from average weather may occur without frarning, the results may be catas. trophic. Indian fear of flood and drought and of other woaber extremes made it imperative that there shouldhe some organised study of weather in relation topops, and a recently published report* surveys th activities of the Agricultural Meteorology Branch of the India Meteorological Department set up for this purpose in 1932.

The survey is in two sections : the first gives the history of the formation of the Branch, a statement of its objects and a general review of work done up to 1946 ; the second gives a more detailed account of recent activity. One might reasonably expect to find some indication of the impact of the first sixteen years of work on Indian farming; but the main emphasis is on what was planned, much less on results obtained, and there is none on the application of the results. The report is completed by eleven appendixes, mainly reprints of scientific papers pub. lished during the period 1946-48. In the first of these appendixes is a description of the Indian Crop Weather Scheme, and the report notes with natural pride that this scheme was adopted for world use by the International Commission of Agricultural Meteorology at Toronto in 1947. Aiming at the collection of relevant crop and weather data throughout the growing year at a network of stations, the scheme differs only in non-essential details from the British Crop Weather Scheme started in 1922. As this has been as near a failure as human pride will ever admit, it seems a pity that an international conference should agree to a world-wide experiment without first being sure that it can be successfully carried out in at least one place. The British Scheme broke down on the biological side, and in this Indian report there are several hints of difficulties being met in the estimation of "the state of the crop".

An interesting aspect of the work of the Agricultural Meteorological Branch is its attempt to establish a weather service for farmers; when the service has been in operation for some years, a critical account of its running (including failures as well as successes) will be of immense value to agricultural meteorology. Seven regional forecast centres have been set up to issue detailed weather bulletins and warnings to farmers, and the centres are being supplied with "Crop Weather Calendars" showing the life-history of the chief crops of the region, their normal weather requirements, and the abnormal weather for which warnings are necessary at different periods during growth. This experiment might well be tried elsewhere, and even in Great Britain the regional division should be regarded as an essential part of the scheme.

The remainder of the report is largely concerned with the work of the observatory at Poona, set up in 1933. Again the account is mainly of activity, without any attempt at a synoptic survey; but there is an impressive list of research problems being investigated in the main branches of agricultural meteorology, with an understandable emphasis on the physical problems of the heat balance and the water balance of the soil, turbulent diffusion and the

* India Meteorological Department. Report on Agricultural Meteor. 
design of new instruments. The 1946-48 section gives more detail than one normally expects in a director's report; but this detail includes some interesting tables of night radiation to cloudy and clear skies, tables of root development and crop growth as a function of depth of water-table, and comparative readings for different types of evaporimeters. It is to be regretted, however, that physicists should waste their time on the Piche and Wild instruments.

Farming is impossible without water, and much of the Poona research is concerned with the hydrological cycle; but there does seem to be a certain lack of self-criticism over fundamentals. An evaporation map of India, calculated in 1934 from an American empirical formula, was still in use in 1946 (Appendix 2). As this shows regions having more than 150 in. evaporation in a year, one feels that the Indian workers themselves might have asked where the necessary latent heat comes from, and to have made some assessment of the meaning and reliability of the estimate; their failure to do so gives a clue to the source of the chief disappointment felt in reading this report. There is little evidence of any integration of the many lines of work-all good in themselvesand while 207 publications in the period look impres. sive as a total, there are too many snippets and too many repetitions. By decreasing the quantity, a considerable increase in quality could be achieved, and what is good work would become magnificent. It would be a tragedy, in India as elsewhere, if either the Poona workers or the Indian Government came to measure the worth of this very valuable research organisation by the annual number of publications.

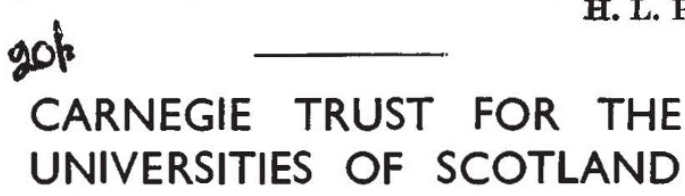

$\mathrm{T}$ WE forty-seventh annual report of the Carnegie Trust for the Unimersities of Scotland for the year 1947- 8 refgrsuto the loss sustained by the death of the chaikr in the Trust, Sir Robert B. Greig, on $\mathrm{N} 0 \mathrm{v}$ mider 9.47 . He has been succeeded by Sir Johr Ircland Fuconer.

In the field of research, demands for assistance with travel and maintenance grants increased, and the executive granted $\mathfrak{\$ 4 , 0 0 0}$ to supplement university funds for assisting professorial and non-professorial staff in this way. Special grants were made to St. Andrews for the purchase of four Bell-Gaumont projectors with accessories ; to Glasgow for electrophoresis apparatus for the Department of Biochemistry; to Aberdeen for maintenance of the swimming pool at King's College to permit free use ; and to Edinburgh for provision of equipment for linguistic and folk-lore recording in both Gaelic and Scottish areas. Assistance given to students decreased by $£ 7,992$ to $£ 43,040$, the number of beneficiaries decreasing from 3,068 to 2,368 ; repayments by former beneficiaries also decreased to $£ 2,634$, from fifty-four beneficiaries.

Details of the eighth quinquennial distribution (1947-52) are given in an appendix. They include $£ 33,650$ to the St. Andrews Centre, of which $£ 12,000$ is for housing for university staff, $£ 5,500$ for scientific equipment, mainly for research, and $£ 6,600$ for equipment for the Advanced Medical School and £13,350 for University College, Dundee, of which $£ 2,350$ also is for scientific equipment, mainly for research. Grants to the Glasgow Centre include $£ 70,000$ to the University towards erection of the final portion of the Chemistry Institute, $£ 5,500$ to the Royal Technical College for the development of a College library service, $£ 2,500$ to the West of Scotland Agricultural College and $£ 3,000$ to the Scottish Miarine Biological Association for renovating the aquarium at Millport Station. Grants to the Aberdeen Centre include $£ 5,000$ to the University for library books, $£ 42,000$ towards the cost of a new Chemistry Department, $\mathfrak{£ , 0 0 0}$ for equipment for the Mechanical Engineering Department of Robert Gordon's Technical College, $£ 1,000$ each to the North of Scotland College of Agriculture and the Macaulay Institute for Soil Research, and $£ 2,000$ to the Rowett Research Institute. Grants to the Edinburgh Centre include $£ 23,000$ to the University for library expenditure, $£ 20,000$ for a lectureship in phonetics and $£ 25,000$ for capital expenditure on the Bush and Dryden estates, $£ 5,000$ to the Heriot-Watt College for special equipment in the Mechanical Engineering Depart. ment, and $£ 2,000$ each to the School of Medicine of the Royal Colleges, the Royal (Dick) Veterinary College and the Edinburgh Dental Hospital and School.

The new scheme for the award of fellowships, scholarships and grants for research is again appended, with details of awards made for the year 1948-49, and a list of publications from beneficiaries during 1947-48. In a note on the work of investigators under the research scheme during the year, reference is made to that of Dr. T. S. Hutchison on the strain sensitivity of magnetic susceptibility, of Mr. F. B. Stern on the crystal structure of tartaric acid, of $\mathrm{Mr}$. E. Reid on the diabetonic principle of the anterior pituitary body, and of Miss D. C. Gibb's progress in her investigations on free-growing fucoid algæ. Dr. C. C. Forsyth has contimued an intensive study into the place of free diet in the treatment of diabetus mellitus, Mr. J. B. Wilson his investigations of the rates of absorption of different amino-acids of different molecular weight from the intestine of the rat and cat, and Miss R. M. Campbell her study of the effects of various factors on the structure of the liver.

Work in chemistry has chiefly been a consolidation of earlier studies, but special mention is made of Mr. G. W. Youngson's work on polymerization, in which he has built up, on the basis of the pentaerythritol molecule, remarkable 'cruciform' macro. molecules in which four big chains of approximately equal length, built up of alternate glycol and adipic acid residues, radiate from a single carbon atom, and more recently, on the dipentaerythritol and trimethylolpropane molecules as bases, six-rayed star. shaped and 'double-Y-shaped' molecules. Mr. C. T. Dickson has continued to work on the structure of colchicine, and Mrs. Storey and Miss B. Cairns on the synthesis of benzacarboline and methoxybenzcarboline and of benzacridone analogues of mepa. crine as of possible interest as anti-malarials.

Dr. A. Lamont's work on the rocks in the Pentland Hills assigned to the Silurian system has led to a tentative opinion that the rocks are of earlier date than has generally been accepted. Dr. F. H. Stewart has proved the presence in the complex of basic rocks at Belhelvie, near Aberdeen, of a type of banding, attributed to gravitational settling, that seems to be paralleled in other parts of the world. The Trust has given important aid in the publication of 